\title{
Expanding universal health coverage among refugees and migrants: challenges and opportunities ${ }^{1}$
}

Citation: Expanding universal health coverage among refugees and migrants: challenges and opportunities. East Mediterr Health J. 2021;27(4):427-428 https://doi.org/10.26719/2021.27.4.427

Copyright (c) World Health Organization (WHO) 2021. Open Access. Some rights reserved. This work is available under the CC BY-NC-SA 3.0 IGO license (https://creativecommons.org/licenses/by-nc-sa/3.0/igo).

\section{Introduction}

The Sustainable Development Goals (SDGs) provide an opportunity for the international community to address migration health issues, particularly through targets 3.8 (achieve universal health coverage [UHC], including financial risk protection, access to quality essential health care services, and access to safe, effective, quality and affordable essential medicines and vaccines for all) (1); and 10.7 (facilitate orderly, safe, regular and responsible migration and mobility of people, including through the implementation of planned and well-managed migration policies) (2).

The inclusion of refugees and migrants in strategic health-care planning and delivery is of particular relevance to the WHO Eastern Mediterranean Region where they constitute a sizable population and are often vulnerable to poor health due to living conditions and limited access to quality health care and other social services. At a time when the Region is facing the challenges of the COVID-19 pandemic, exclusion makes the implementation of prevention and control measures among refugees and migrants more difficult, increasing the risk of the pandemic spreading among these populations, in host countries and in countries of return.

To mark Universal Health Coverage Day $2020(12$ December), a roundtable discussion was held on 10 December 2020 as part of a series of events bringing health partners and stakeholders together to review and discuss the opportunities and challenges facing the expansion of UHC in the Region (3).

The event was co-organized by the WHO Regional Office for the Eastern Mediterranean, International Organization for Migration (IOM) Regional Office for the Middle East and North Africa, UN High Commission for Refugees (UNHCR) Middle East and North Africa, and United Nations Relief and Works Agency for Palestine Refugees (UNRWA).

The objectives of the meeting were to:

- identify opportunities for collective actions by health actors at regional and country levels to expand UHC among refugees and migrants;
- identify lessons learned and good practices employed to date.

\section{Summary of discussions}

Participants agreed that a set of entitlements based on 'Health for All' (4) is required, must be applied with equity to all including internally displaced persons, refugees and migrants, and that financing must be supported by partners. To meet these demands, WHO is working towards finding innovative ways to ensure that this becomes a reality. The impact of the COVID-19 pandemic on the Region is in addition to an unprecedented set of health-care emergencies (5). Meanwhile, GAVI announced plans to allocate $5 \%$ of all vaccines that come through the COVAX facility to high-risk populations in humanitarian settings (6). Participants also agreed that UHC is the key strategy to promoting the health of refugees and migrants, which requires the integration of refugee and migrant health considerations into national policies and strategies and ensure that "no-one is left behind" (7).

\section{Recommendations}

1. Promoting migrant-inclusive health policies and migrant-friendly services as a critical aspect of UHC;

2. adopting a holistic approach to UHC that views migration as a social determinant of health, and acknowledges how and where people migrate directly impacts the health of migrants;

3. strengthening regional partnerships and cooperation on borders and along mobility corridors;

4. establishing a new "normal" for health care settings and streamlining primary health care provisions;

5. including all refugees and migrants in COVID-19 vaccine campaigns;

6. strengthening data collection and management regarding migrant health for the effective inclusion of migrants into national health policies and programming;

7. fostering closer working practices with academia to review responses to the pandemic provided by national health systems, UN agencies and partners, and to identify lessons learned.

\footnotetext{
This summary is extracted from the Report on the roundtable discussion on Expanding universal health coverage among refugees and migrants: challenges and opportunities, 10 December 2020 (https://applications.emro.who.int/docs/WHOEMEHSoo3E-eng.pdf?ua=1).
} 


\section{References}

1. United Nations. Target 3.8: Achieve universal health coverage, including financial risk protection, access to quality essential health-care services and access to safe, effective, quality and affordable essential medicines and vaccines for all. New York: United Nations; 2021 (https://unstats.un.org/sdgs/metadata/?Text=\&Goal=3\&Target=3.8).

2. United Nations. Target 10.7: Facilitate orderly, safe, regular and responsible migration and mobility of people, including through the implementation of planned and well-managed migration policies. New York: United Nations; 2021 (https://unstats.un.org/ sdgs/metadata/?Text=\&Goal=10\&Target=10.7).

3. World Health Organization Regional Office for the Eastern Mediterranean (WHO/EMRO). Report on the roundtable discussion on Expanding universal health coverage among refugees and migrants: challenges and opportunities. Cairo: WHO/EMRO; 2020 (https://applications.emro.who.int/docs/WHOEMEHSoo3E-eng.pdf?ua=1).

4. World Health Organization. Priorities: Health for All. Geneva: World Health Organization; 2020 (https://www.who.int/dg/priorities/health-for-all/en/).

5. World Health Organization Regional Office for the Eastern Mediterranean (WHO/EMRO). Health emergencies 2018 annual report. Cairo: WHO/EMRO; 2018 (https://www.emro.who.int/annual-report/2018/health-emergencies.html).

6. GAVI. The COVAX humanitarian buffer explained. Geneva: GAVI; 2020 (https://www.gavi.org/vaccineswork/covax-humanitarian-buffer-explained).

7. United Nations. Leaving no one behind. New York: United Nations; 2018 (https://sustainabledevelopment.un.org/content/documents/2754713_July_PM_2._Leaving_no_one_behind_Summary_from_UN_Committee_for_Development_Policy.pdf). 